\title{
Prevenção quinquenária: prevenir o dano para o paciente, actuando no médico
}

José Agostinho Santos*

A $\mathrm{s}$ actividades preventivas adquirem uma grande dimensão no quotidiano clínico do médico. ${ }^{1}$ Quatro níveis de prevenção são classicamente descritos na literatura: primária, secundária, terciária e quaternária. ${ }^{2-3}$

Qualquer um destes níveis de prevenção adquire uma importante expressão nas decisões clínicas sobre o paciente e sobre a relação médico-paciente. O potencial para uma boa razão benefício/custo destas decisões está retido numa medicina centrada no paciente. ${ }^{3-6}$ No entanto, as definições das actividades preventivas nestes quatro níveis parecem partir do princípio garantido de que o médico, como elemento único, é alicerce estável desde que seja possuidor da melhor evidência científica e/ou desde que seja praticante dos princípios éticos que deverão reger o seu exercício profissional. Se assim não for, poderá ser considerado desactualizado e/ou disruptor do juramento de Hipócrates.

Por outro lado, a relação médico-paciente e o paciente são ambos mutáveis, pelo que os outcomes negativos que possam emergir inesperadamente com as atitudes preventivas (primárias, secundárias, terciárias ou quaternárias) serão entendidos e não-puníveis (uma vez que a mutabilidade traz alterações que não puderam ser consideradas no início das decisões clínicas). Nos dias de hoje poder-se-á discutir as melhores medidas para identificação e posterior resolução e prevenção de questões relacionadas apenas com o médico. Nesta sucessão de diferentes degraus de prevenção propõe-se aqui uma última mas não menos importante plataforma relacionada com a prevenção do burnout que consome a estabilidade do médico (conduzindo a uma mutabilidade de cariz negativo). O burnout é definido como um estado de plena exaustão física e/ou

*Assistente de Medicina Geral e Familiar USF Dunas, Lavra, ULS - Matosinhos psicológica que germina da produção contínua e intensiva de respostas concertadas perante as elevadas exigências no local de trabalho. ${ }^{7-8} \mathrm{~A}$ exaustão equipara-se ao sobreaquecimento de um equipamento em sobreuso. Ora, o uso excessivo dos recursos tanto materiais como humanos, testando os limites, constitui uma tentação para a qual alguns administradores ou gestores poderão facilmente ceder. Entender-se-á, sob um falso princípio, que o sobreuso será rentável. No caso particular dos médicos, o sobreuso da sua actividade (número crescente de pacientes, encurtamento do tempo de consulta, sobrecarga de horas extraordinárias) poderá ser entendido como rentável para a instituição, assim como favorecedor de uma maior acessibilidade dos pacientes aos serviços da unidade. Nesta linha de pensamento estarão apenas medidos resultados intermédios. Na realidade, a meta final (qualidade de cuidados prestados com repercussão global no estado de saúde do paciente) não é avaliada.

O risco do burnoutnão é, portanto, contemplado por se entender, talvez, que tal é do foro pessoal exclusivo do médico. De facto, nos dias actuais e apesar de tanto se falar das consequências do burnout, os médicos sentem que pouco se valoriza a prevenção do seu burnout como parte da prevenção de problemas de saúde para os pacientes. ${ }^{9}$ Mas, na verdade, a prevenção do burnout delineia-se num fluxo particular: prevenir o dano para o paciente, actuando no médico. Esta actuação diferencia-se de qualquer das outras categorias de prevenção (que se centram no campo biopsicossocial do paciente e na relação médico-paciente). Poder-se-á dizer que constitui uma prevenção a um quinto nível e denominar, quiçá, de prevenção quinquenária.

Interessam aqui as questões como o erro médico. As medidas em prevenção quinquenária poderão conduzir a um incremento da motivação dos médicos, maximização dos raciocínios clínicos correctos (que, por sua 
vez, conduzam ao diagnóstico definitivo o mais precocemente possível), aumento da fluidez na comunicação entre estes profissionais de saúde e possivelmente trarão uma multiplicação dos lucros económicos inerentes às atitudes médicas assertivas e efectivas. ${ }^{10-12} \mathrm{Ape}$ sar de também protegerem o paciente do dano, estas medidas distinguir-se-iam da prevenção quaternária devido a dois aspectos: 1) a prevenção quinquenária actuaria exclusivamente no campo biopsicossocial do médico; 2) a prevenção quaternária emerge de acções sobre as convicções clínicas sem benefícios comprovados (mas que são tidas, pelos médicos portadores, como condutoras a boas práticas), enquanto a prevenção quinquenária emerge de acções que evitam práticas involuntariamente incorrectas.

Não constitui um pressuposto dos manuais de ética que o médico seja incansável e inesgotável. ${ }^{13} \mathrm{O}$ burnout é expectável perante condições que favoreçam a sua germinação e poderá originar outcomes negativos que não são devidos a desactualização científica ou nãocumprimento dos princípios éticos. Tal inclui o erro médico honesto, em que os profissionais falham num plano mas cumprem as regras de actuação, a leges artis. $^{14}$ Este erro é compreendido, mas deixa de ser alvo de prevenção (novamente: prevenção quinquenária).

Tenhamos, como exemplo, um quadro comum: o doente dependente e o seu cuidador. O médico terá uma atitude clínica a nível do cuidador enquanto individualidade única, que se acrescenta à atitude clínica a nível da interacção cuidador-doente e do doente. Não cabe ao médico iniciar acções no sentido de transformar uma pessoa próxima do doente num cuidador nato: a existência de um potencial para cuidar é um pressuposto exigido automaticamente a essa pessoa próxima, assim como é a entrega ao princípio ético de cuidar bem e não praticar o mal ao doente. Porém, cabe ao médico uma atitude que promova a expressão máxima desse potencial e dessa entrega, motivando o cuidador e prevenindo o seu desgaste. ${ }^{14-15}$ Ora, o médico é como um cuidador. Isto quererá dizer que as medidas nesta prevenção quinquenária não passam por criar actividades de estímulo à actualização científica ou ao cumprimento dos princípios éticos do cuidar, mas por estratégias que conduzam à evicção do erro que surge de uma deterioração do bem-estar biopsicossocial do médico.
A literatura é pródiga em artigos que abordam estratégias (com ou sem evidência comprovada) que alarguem a possibilidade de prevenção do burnout e/ou evicção os erros médicos. ${ }^{8-12}$ Estes erros poderão ocorrer durante o exercício profissional de médicos actualizados e que cumprem os fundamentos éticos. Foram já desenvolvidos uns poucos estudos no sentido de avaliar o impacto dessas estratégias na prevenção de resultados menos bons, algo que, em primeira instância, vai ao encontro do conceito da prevenção quinquenária. Se é certo que parte dos erros médicos brotam da ausência dos tais princípios fundamentais do código deontológico, também é conhecido que uma boa parte surge em contextos onde esses pressupostos estão bem vigorosos, ocorrendo falhas na dependência de outras circunstâncias. ${ }^{10-12}$

As estratégias no âmbito da prevenção quinquenária já existem na prática, faltando possivelmente a sua categorização e denominação para que sejam concretamente percepcionadas por todos os intervenientes num Sistema Nacional de Saúde. Elas desenrolam-se em quatro esferas: ${ }^{8,10-12}$

1. Médico: estratégias que têm, como objectivo final, criar alterações ou manutenções favoráveis dos aspectos intrínsecos e biopsicossociais do médico, enquanto pessoa (existe uma componente afectiva no raciocínio médico);

2. Paciente/Comunidade: estratégias que visam gerar mudanças na comunidade onde o médico pratica o exercício profissional, de maneira a criar uma maior fluidez da relação médico-paciente;

3. Local de trabalho: estratégias que pretendem criar modificações a nível do local de trabalho que favoreçam a maximização do potencial profissional (recursos humanos, equipamento necessário no gabinete, adequabilidade dos sistemas informáticos de suporte à prática clínica, proximidade de outras especialidades médicas para referenciação e/ou discussão quanto à decisão clínica, protocolos de actuação clínica);

4. Administração/Governo: estratégias que vão ao encontro da satisfação do médico enquanto empregado de uma entidade que o contrata (nomeadamente, o fornecimento de redes de suporte às suas actividades).

As duas últimas esferas constituem, simultanea- 
mente, campos de desenvolvimento de estratégias de governação clínica, definida como o processo através do qual "as organizações prestadoras de cuidados de saúde são responsáveis pela melhoria contínua da Qualidade dos seus serviços e pela garantia de elevados padrões de cuidados, criando um ambiente que estimule a excelência dos cuidados clínicos. ${ }^{15}$ A questão que eleva é: estarão estas organizações a desenvolver estratégias que estimulem a excelência dos cuidados prestados? O conceito da prevenção quinquenária é assim proposto, salientando o potencial para investigação existente nesta área. Tal como qualquer das outras categorias preventivas, a evicção do dano para o paciente constitui o objectivo tão final quão primordial.

\section{REFERÊNCIAS BIBLIOGRÁFICAS}

1. Canadian Medical Association. The role of physicians in prevention and health promotion (update 2001). Ottawa: CMA; 2001.

2. RACGP National Standing Committee. The role of general practice in prevention and health promotion. Melbourne: Royal Australian College of General Practitioners; 2006.

3. Melo M.A prevenção quaternária contra os excessos da medicina [Quaternary prevention against excessive medical intervention]. Rev Port Clin Geral. 2007;23(3):289-93. Portuguese

4. Bentzen N, editor. WONCA international dictionary of general/family practice. Copenhagen: Maanedskift Lager; 2003.

5. Moynihan R, Doust J, Henry D. Preventing overdiagnosis: how to stop harming the healthy. BMJ. 2012;344:e3502.

6. Almeida LM. Da prevenção primordial à prevenção quaternária [From primordial to quaternary prevention]. Rev Port Saúde Pública. 2005;23(1):91-6. Portuguese

7. Lee RT, Seo B, Hladyj, Lovell BL, Schwartzmann L. Correlates of physician burnout across regions and specialties: a meta-analysis. Hum Resour Health. 2013;11:48.

8. Meldrum H. Exemplary physicians' strategies for avoiding burnout. Health Care Manag. 2010;29(4):324-31.

9. Yaphe J. On the health of doctors: why we need to look after ourselves first. Rev Port Med Geral Fam. 2013;29(2):86-7.

10. Lorincz CY, Drazen E, Sokol P, Neerukonda KV, Metzger J, Toepp MC, et al. Research in ambulatory patient safety 2000-2010: a 10-year review. Chicago, IL: American Medical Association; 2011.

11. Schiff GD, Hasan O, Kim S, Abrams R, Cosby K, Lambert BL, et al. Diagnostic error in medicine: analysis of 583 physician-reported errors. Arch Intern Med. 2009;169(20):1881-7.

12. Gandhi TK, Kachalia A, Thomas EJ, Puopolo AL, Yoon C, Brennan TA, et al. Missed and delayed diagnoses in the ambulatory setting: a study of closed malpractice claims. Ann Intern Med. 2006;145(7):488-96.

13. Ordem dos Médicos. Aprova o código deontológico da Ordem dos Médicos: regulamento n. ${ }^{0}$ 14/2009, de 13.01.2009.

14. Fragata J. A segurança dos doentes: indicador de qualidade em saúde [Patient safety and health care quality]. Rev Port Clin Geral. 2010;26(6):564-70. Portuguese

15. Santos I, Sá E. Estratégias de governação clínica [Clinical governance strategy]. Rev Port Clin Geral. 2010;26(6):606-12. Portuguese

\section{CONFLITOS DE INTERESSE}

O autor declara não ter conflitos de interesse.

\section{ENDEREÇO PARA CORRESPONDÊNCIA}

E-mail: zeagostinho@hotmail.com 